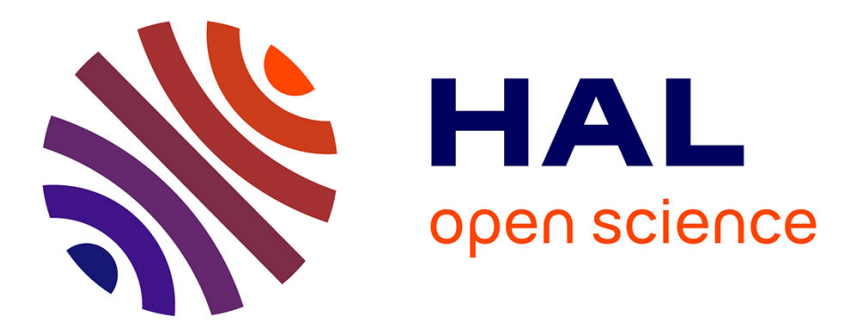

\title{
Grasping an object at floor-level: Is movement strategy a matter of age?
}

\author{
Martine A. Gilles, Pascal Wild
}

\section{To cite this version:}

Martine A. Gilles, Pascal Wild. Grasping an object at floor-level: Is movement strategy a matter of age?. Applied Ergonomics, 2018, 70, pp.34 - 43. 10.1016/j.apergo.2018.02.002 . hal-01912635

\section{HAL Id: hal-01912635 \\ https://hal.science/hal-01912635}

Submitted on 5 Nov 2018

HAL is a multi-disciplinary open access archive for the deposit and dissemination of scientific research documents, whether they are published or not. The documents may come from teaching and research institutions in France or abroad, or from public or private research centers.
L'archive ouverte pluridisciplinaire HAL, est destinée au dépôt et à la diffusion de documents scientifiques de niveau recherche, publiés ou non, émanant des établissements d'enseignement et de recherche français ou étrangers, des laboratoires publics ou privés.

\section{(1) (1) $\$$}

Distributed under a Creative Commons Attribution - NonCommercial - NoDerivatives| 4.0 
Grasping an object at floor-level: Is movement strategy a matter of age?

Martine A. GILLES and Pascal WILD

Département Homme au Travail, INRS Lorraine, 1, rue du Morvan, CS60027, 54519 Vandœuvre

Cedex, France

martine.gilles@inrs.fr

\title{
Highlights
}

- 7 postural strategies to pick up parts were identified based on simultaneous analysis of 17 kinematics variables.

- Most operators used more than one strategy when collecting parts.

- No strategy was observed to be specific to a particular age group.

- The number of strategies used by an operator decreased with increasing age.

\begin{abstract}
Bending down to pick things up off the floor is something that we do every day. This multisegment task can be done in a considerable number of postural configurations because of the large number of degrees of freedom to be controlled when executing it. In this study where volunteers performed a repetitive bending task, multisegment kinematic analysis allowed us to identify seven different bending strategies. Most operators used more than one bending strategy, but no particular strategytype was found to be specific for a specific age group. However, the number of strategies used by an operator decreased with increasing age. It therefore appears that this factor influences the variability of the strategies used when repeatedly executing a movement involving the lower limbs to collect small objects from floor-level. This decrease in movement variability in senior operators may contribute to their increased risk of developing musculoskeletal disorders.
\end{abstract}

Key words: bending strategy, age, work pace, squat and stoop

\section{Introduction}

Picking objects up off the floor is an action that we perform every day. Adult humans are familiar with this movement and no longer need to learn it. However, this multisegment task can take a considerable number of postural configurations as there are a large number of degrees of freedom to control when executing it. The action of squatting has been the subject of a large number of studies aiming to determine the biomechanical constraints on the lumbar region during transport of heavy loads (Anderson and Chaffin 1986, van Dieën 1999, Sheppard 2012). Three types of lifting techniques have often been compared: the squat, the semi-squat, and the stoop (Burgess-Limerick and Abernethy 1997, van Dieën et al. 1999, Straker 2003). Several studies have compared the respective benefits and advantages of these different techniques, and various factors have been found to promote use of one or the other. Some of these factors are linked to the object carried - such as its weight (Hoozemans et al. 2008), how cumbersome it is, the height from which it must be collected and that at which it must be deposited (Burgess-Limerick et al. 2001), the speed of transfer (Lin et al. 
1999) or its trajectory (de Looze et al. 1998) - while others correspond to the functional capacities of the carrier - such as their gender (Lindbeck and Kjellberg 2001, Plamondon et al. 2014b, Sheppard et al. 2016) or age (van Dieën et al. 1994), the muscles solicited (Trafimow et al. 1993), the physiological cost (Kumar 1984), the oxygen consumption during the exercise (Hagen and HarmsRingdhal 1994) or how much experience the carrier has with transporting heavy loads (Plamondon et al. 2010, 2014a). This last point illustrates how expertise causes carriers to adapt their posture depending on the context, as determined by the object (weight, dimensions, fragility) or the trajectory to be covered between the initial point and the destination.

In these previous studies, the expertise which determines how the carrier moves appears to be closely linked to the characteristics of the object to be transported. But what variations in movement would be observed if the external constraints such as the volume of the object, or its weight, were no longer the main constraints for the task? In this type of situation, internal constraints, directly linked to the subject such as age (which could influence their functional capacities), appear to be one of the most significant factors determining the variability of the final movement (Gaudez et al, 2016). These constraints take on even greater importance in the current socio-economic context where older workers remain at work for longer. With advancing age, changes to muscle properties can combine with a worker's capacity to repeat a physically demanding movement, such as collecting objects from the floor (Duchateau et al. 2006, Gibo et al. 2013). The capacity to repeat this movement will be all the more hampered when a rapid work pace is added to age-related constraints (Gilles et al., 2017). Nevertheless, numerous elements remain to be modulated when performing the movement. For example, the trajectories of the limbs are involved, the speed of execution and any obstacles that must be avoided have to be considered (Rosenbaum et al. 2001). Planning a movement also involves a conscious decision to grasp an object with the aim of doing something with it. This aspect gives sense to the movement (Bril and Goasdoué 2009, Bril 2015). To study and analyse motor variability, it is important to provide the means to give sense to a movement when planning it. It was with this objective in mind that the task analysed in this study was designed. The task involves collecting parts stored at floor-level, for their assembly with another part on a mounting table.

A previous paper presented results from classical movement analysis performed on the same task (Gilles et al., 2017). This exhaustive analysis of the data provided us with an extensive range of information through which we could understand the physiological limitations involved in performing a task requiring squatting. These limitations were determined by the age of the person executing the task and/or the pace of the work. However, examining the different joints independently makes it difficult to understand the overall posture adopted when performing a task. Thus, a certain number of questions relating to the segmentary strategy implemented when collecting the parts could not be solved by this method. Indeed, the disparity of results obtained during the first analysis suggested the existence of intra-subject postural variability, but also of inter-subject postural variability determined by internal factors, such as age, or external factors, such as pace. In this paper, we hypothesize that the disparity of results observed might be due to a series of co-existing strategies.

The objective of the work described in this paper was to perform a multisegment analysis to better identify the postural strategies adopted during the task requiring collection of objects placed at floorlevel. With respect to these strategies, the questions were twofold: First, is there a dominant strategy characteristic of each age group? Second, does the same person use more than one strategy? And, if 
more than one strategy is identified, what is level of variability in these strategies? Is this level of variability influenced by age or the pace of work?

\section{Methods}

Participants

Sixty-three right-handed men voluntarily participated in this experiment. Volunteers were recruited based on two main selection criteria. First, subjects had to be in one of the three following agegroups: junior (J) from 30 to 35 years old, median (M) from 45 to 50 years old, or senior (S) 60 to 65 years old. The characteristics of subjects in each of these age-groups are presented in Table 1 . In addition, all subjects had to have worked or still be working in what is considered a "physically demanding" job to ensure relatively homogeneous evolving functional capacities. Volunteers were recruited either through temporary employment agency or through advertisements published in local newspapers. Participants' functional capacities were assessed before the experiment based on tests of flexibility, dexterity (based on the Purdue pegboard test (Desrosiers et al., 1995)), speed of upper limb movement, and analysis of the muscular force of the upper and lower limbs. All subjects gave their free and informed consent for participation in this study, the protocol for which was approved by the ethics committee for biomedical research at our Institute.

\section{Procedure}

Subjects were asked to perform an assembly task in conditions similar to those encountered at an assembly-line workstation. The height of the workstation was adapted to the size of each subject. The task involved several successive actions executed in a cyclic and repetitive manner at a defined work pace. A single assembly cycle involved collecting an assembly base from a distributor/collector of parts, moving between the distributor and the workstation, collecting parts stored at floor-level under the assembly table, assembly of the parts with the base on the worktable, and finally, once all parts had been assembled, return to the distributor/collector (Figure 1). In this paper, analysis focused on the action of collection of the parts, one handle ( $200 \mathrm{~g}$ ) and two nuts ( $7 \mathrm{~g}$ each), stored under the workstation. No recommendations were made on how to proceed when collecting the parts stored at floor-level. The only obligation was that, during each assembly round, the precise number of parts required should be collected, rather than amassing a reserve for subsequent assembly tasks.

The repeated assembly cycles, which included collection of spare parts from the floor-level reserve, were performed during two work sessions, each of which lasted 20 minutes. For each of these sessions, a different work pace was imposed by the base distributor. Subjects had access to real-time visual information on their progress with respect to the prescribed work pace. The pace was either comfortable, corresponding to 25 seconds per assembly cycle, i.e., a total of 49 assemblies, or rapid, at 20 seconds per assembly cycle, i.e., 60 assembly cycles to be completed. The order in which sessions were completed was randomised, but as many subjects from each age-group started by one or other of the paces. The pace was monitored continuously throughout the work session. A verbal reminder of the requirement to maintain the pace was given to subjects if they slowed down. 


\section{Apparatus}

The postures adopted during repeated assembly cycles involving collection of parts from floor-level, were video recorded throughout the experimental sessions.

3D modelling of each assembly cycles was computed with Motion Inspector ${ }^{\circledR}$ software. Modelling was based on three superimposed models: i) an anthropometric model using 67 anthropometric measurements for each subject (Hanavan, 1964); ii) an inverse dynamic model using the forces and moments exerted at ground-level, as recorded using an AMTI®-type force plate, and the forces and moments exerted on the assembly table, recorded using an ATI® sensor. All dynamic signals were recorded at a frequency of $200 \mathrm{~Hz}$. iii) a kinematic model using the displacement of 37 passive markers - placed on the subject in relation to anatomical landmarks - measured at a frequency of $50 \mathrm{~Hz}$ using an optoelectronic system (Vicon 460®). These three combined models allowed us to compute 14 body segments (two feet, two legs, two thighs, one pelvis, one abdomen, one thorax, two arms, two forearms, and one head) and to reconstruct joint centres corresponding to the joints linking the different segments.

Among all of the variables modelled, 17 were selected to characterise the movement involved in collecting the spare parts. These variables were measured and calculated from an orthonormal reference position (Figure 2a). The variables were as follows:

- the amplitude of downwards motion of the joint centre for the sacrum. This measurement corresponds to the difference in vertical position of the joint centre for the sacrum between the upright posture and the posture at its lowest point relative to the ground during collection of the parts.

- the distances between the joint centres for the right and left toes and between those of the right and left knees, relative to the anteroposterior, medio-lateral and vertical axes, and the distances between the joint centres of the heels relative to the medio-lateral and vertical axes. These distances were measured when the sacrum was located at its lowest point relative to the ground. They were used to record differences in position between the joint centres associated with the lower left limb and those associated with the lower right limb. They were calculated for each test and relative to each of the axes. The anteroposterior distance between the heels was not included among the variables as it was redundant with the anteroposterior distance between the toes. Therefore, it would have given too much weight to this information in the analysis. A positive distance indicates that the lower left limb is located anterior to the anteroposterior axis, or higher relative to the vertical axis, than the lower right limb.

- the Euler angles for flexion of the ankles, knees and hips, as well as the abduction angles for the hips. These angles were calculated in line with the recommendations provided by the International Society for Biomechanics (Wu \& Cavanagh, 1995, Wu et al., 2002). The angles were measured when the joint centre of the sacrum was located at its lowest point relative to the ground, and were compared to those measured for the reference posture (subject standing upright, arms aligned with the trunk) recorded at the start of the experimental session. The detailed procedure through which the angles were calculated was presented for the kinematic analyses of the full assembly task (Gilles et al., 2017). 
Statistical analysis

All statistical analyses were carried out using Stata software (StataCorp LLC, Tx). The first objective of the analysis was to identify postural strategies. An agglomerative hierarchical clustering method based on the Euclidean distance was performed. This clustering algorithm was based on 17 variables after normalisation of each variable, using a complete linkage algorithm that is using the farthest pair of observations between two groups to determine the proximity of the two groups. This normalisation consisted in substracting from each variable its overall mean and dividing by the overall standard deviation. This classification aims to identify, from all the recordings analysed, the different categories of movement used when collecting parts. The strategies were characterised by a side-toside box plot of the 17 variables on which they were based. From these box-plots, each strategy was assigned a posture name. The posture names were validated by both the video and the model.

The second objective was to assess whether the dominant strategy (the strategy that was most often employed) is characteristic of the age group in both paces. The dominant strategy was cross-tabulated with the age-group by work pace. The association was tested for each table using Fisher's exact test. A more formal approach was based on a mixed effect multinomial logistic regression fitted using a generalized structural equation model (stata command gsem).

The third objective was to document the level of variability observed in the strategies used. In order to do so, the number of strategies used was cross-tabulated with the age-group by pace and with pace. Each table was tested using Fisher's exact test. A more formal approach was based on a mixed effect Poisson regression model (stata command mepoisson). In this model both main effects with and without interactions were tested.

\section{Results}

\section{Identification and characterisation of strategies}

The agglomerative hierarchical clustering identified seven classes of postures used when collecting parts from floor-level. These strategies were matched with the ones observed during parts-collection when comparing with the video recordings. Segmental postures describing each of these seven strategies could be interpreted from the data presented in boxplots (Figure 2). The dichotomy between squatting and stooping can be observed in Figure 2b, which illustrates the difference in amplitude of vertical displacement of the sacrum. For each strategy, Figure $2 \mathrm{c}$ shows the distribution of the values for the distances between the right and left joint centres for the toes, heels and knees, and Figure $2 \mathrm{~d}$ shows how the values for the flexion angles for the lower limbs and for hip abduction distributed. The order of presentation of the strategies in the classification is arbitrary. A full description of the seven strategies is presented in Figure 3.

For five of the seven strategies, subjects used a large amplitude of flexion of the knees. The different position configurations of the right and left lower limbs distinguish between the squatting techniques in these different strategies. Not all of the mirror strategies between the right and the left were observed. Among the five strategies, three of them are readily distinguished:

- Squat Knees Equally Descended (SKED): in this "sumo"-type position, subjects descend symmetrically by bending their two lower limbs. All of the anteroposterior and vertical distances 
between the left and right joint centres for the toes, the heels and the knees were null, and there was significant abduction of the hips.

- Squat Right Knee Down 1, 2 and 3 (SRiKD 1 to 3): these strategies could be described as a "servant knight" position, with the left foot placed flat on the floor forward of the right foot, which is flexed. The right knee descends towards the ground whereas the lower left limb is at a right angle relative to the ground. The distinctions between the three SRiKD strategies are quite subtle. SRiKD2 is distinguished by the extent of abduction of the hips, whereas the distinction between SRiKD 1 and 3 is linked to an accumulation of small differences across all of the variables analysed.

- Squat Left Knee Down (SLeKD): this strategy is the mirror strategy of the SRiKD strategies, with inversion of the values for the distances which translate the fact that in this position the right foot is placed flat on the ground forward of the left foot; the lower right limb is at a right angle to the ground and the left knee points towards the ground.

The remaining strategies were characterised by significant flexion of the hips combines with only minor flexion of the knees. Among the stooping technique, two strategies were distinguished:

- Mstoop: in this strategy the greatest flexion is at the level of the hips. However, there is still a low amplitude of downwards motion of the joint centre for the sacrum, linked to the low, but symmetrical, amplitude of flexion of the knees.

- Stoop: This strategy is very similar to the previous one, but in this case, there is practically no downwards motion of the joint centre associated with the sacrum.

\section{Dominant strategy by age and pace}

The frequency with which these strategies were observed for each age-group and pace of work is shown in Table 2. In general, and whatever the age-group, no dominant strategy was observed, although the SRiKD1, SRiKD3 and SLeKD strategies were the most frequently observed at both work paces.

At the comfortable pace, the frequency of observation of the strategies was not significantly associated with age $(\mathrm{p}=0.157)$, although the SRiKD3 strategy was more frequently encountered in the junior age-group (35\%) followed by the SRiKD1 strategy $(25 \%)$. The other strategies were more weakly represented (from 5 to $15 \%$ ). The Stoop strategy was never observed in this age-group. For subjects in the median age-group, the SRiKD1, SRiKD2, SRiKD3 and SLeKD strategies were observed in equivalent proportions (20 to 25\%). The SKED and Stoop strategies were only observed in a small number of cases (5\%) and the MStoop strategy was never observed. For the senior agegroup, the most frequently observed strategies were the SLeKD and MStoop strategies (26\% each). The other strategies were rarely observed (4 to 13\%). Even if the predominant strategy does not significantly depend on age-group, it was nevertheless observed that the strategies characterised by a very small angle of flexion at the knees corresponded to $30 \%$ of all movements to collect objects from floor-level at the comfortable pace in the senior age-group, and a much lower percentage in the other two age-groups.

At the rapid pace, the frequency of observation of the strategies was not significantly associated with age $(\mathrm{p}=0.063)$, although the SRiKD3 strategy was still the most frequently encountered in the junior age-group (55\%) followed by the SRiKD1 strategy (20\%). The SRiKD2 and Stoop strategies were never observed with this age-group at this pace. For subjects in the median age-group, the SRiKD1 $(35 \%)$ and SLeKD (30\%) strategies were the most frequently observed, followed by the SRiKD3 
strategy (20\%). The Stoop strategy was not observed at this pace. For the senior age-group, the SLeKD and MStoop strategies were once again observed in the majority of cases (26\% and 22\%, respectively), while the SRiKD2 strategy was never observed. Thus, once again, the predominant strategy used does not significantly depend on the age-group.

All groups combined, few modifications to the frequency of use of the different strategies were observed when the pace of work changed, although the SRiKD2 strategy was less frequently observed at the rapid pace (1.6\%) than at the comfortable pace (12.7\%). Indeed, 41 subjects $(65 \%)$ used the same dominant strategy at the two paces (data not shown). Nevertheless, the analysis of the three age-groups showed some slight but noticeable differences. For the younger age-group, the dominant use at the comfortable pace of the SRiKD3 strategy (35\%) was increased by $20 \%$ at the rapid pace, whereas the use of the SKED strategy dropped by $10 \%$. For subjects in the median agegroup, with the increasing pace, a 10\% accentuation of the use of the SRiKD1 strategy was observed, while the number of observations of use of the SRiKD2 strategy decreased by $15 \%$. For the senior subjects, the use of the SKED strategy doubled while the SRiKD2 strategy was no longer used at the faster pace.

In summary, although some slight differences were observed, the formal regression analysis showed no significant global effect of age or pace in the distribution of the dominant strategies.

\section{Number of strategies observed by age and pace}

The number of strategies used by each age-group at each pace of work is shown in Table 3. The number of strategies used was seen to decrease with age. Overall, the relationship between age-group and the number of strategies used was already significant at the comfortable pace $(\mathrm{p}=0.039)$, and became even more so at the rapid pace $(\mathrm{p}=0.007)$. Thus, we observed that, all age-groups combined, at the comfortable pace the majority of subjects used two to three strategies, whereas at the rapid pace the trend was to use only one or two strategies.

For the junior age-group, a maximum of five strategies were observed for each subject, whatever the pace. The number of strategies used tended to decrease for all age-groups as the pace of work increased.

Applying the formal regression modelling to the number of strategies revealed no significant global effect of pace on the distribution of the number of strategies used, but the number did decrease significantly with age (figure 4).

\section{Discussion}

Our aim was to determine whether, multisegment analysis rather than variable by variable analysis could identify different motor strategies used when performing a movement to accomplish the same goal repeatedly. The strategies identified could then be used to investigate to what extent their use varied between individuals or conditions, and how this variation was linked age or the pace of work.

The method of agglomerative hierarchical clustering used to identify the different strategies implemented by subjects agreed well with visual observations made during the experiments, and with 
the groups of postures calculated. The characterisation of strategies based on box plots representing each of the variables is compatible with the results obtained by kinematic modelling. Indeed, for each collection of parts from floor-level, the segmental positions observed with the kinematics model corresponded to the strategy name.

Seven strategies, five types of squat and two types of stoop, were identified by the multisegment analysis. No strategy was found to be specific of any age-group in any pace. However, older subjects tended to more frequently use strategies requiring less flexion of the knees (MStoop and Stoop). Similar age-related differences in the postural kinematics during repetitive lifting were previously reported (Shin et al., 2006, Burgess et al., 2009, Song and Qu, 2014, Gilles et al., 2017). In all cases, differences were observed between the strategies adopted by older and younger subjects when performing lifting tasks. Different hypotheses were advanced to explain these differences, such as that change could be an adaptation to fatigue or as a means to protect against pain. It is also probable that older subjects adopt strategies with less knee flexion as a result of age-related increased muscle stiffness, reduced speed of muscle contraction and reduced muscular force in the knee extensors (Macaluso and De Vito 2004, Duchateau et al. 2006). The effort required to counteract gravity when raising the bust during the return to an upright position after squatting is also known to be significant (Kumar 1984), and it becomes more intense with increasing age. However, most studies dealing with postural differences during repetitive lifting examined the task as an isolated movement. Furthermore, the position of the feet, imposed by the experimenter, left the subject few possibilities to vary his/her strategy. Our experimental setup, first, left subjects free to choose the position of their feet when performing the task. This allows them more opportunity to be creative when collecting objects from floor-level. Secondly, the collecting task used in this study was part of a succession of tasks. As a result, subjects did not focus their attention on his position when collecting the parts, rather they concentrated on completing the job in the allotted time. Thus, our experimental set-up is thus suitable for observing variability in the movement strategies used to collect parts, in a process mimicking that that would take place in a real-life workplace.

The number of strategies used by each subject appears to be more significant indicator than the actual strategies used. Indeed, this number was observed to significantly decrease with age and at both paces. However, the effect of pace, a slight non-significant reduction in the number of strategies used at the fast pace, was only weakly discernible. It is therefore not possible to confirm the existence of an effect of pace on the number of strategies implemented by the subjects. Despite the large amount of data available in our study, the regression model would require even more data to show a significant effect of pace on the number of strategies used. Several other studies have described motor variability, even when performing repetitive occupational tasks which tend to be very constrained in terms of motricity. This variability was observed both between different operators (Boocock et al., 2015) and for the same operator (Madeleine and Madsen 2009, Madeleine 2010, Mathiassen and Paquet 2010, Wahlstrom et al. 2010, Srinivasan and Mathiassen 2012, Ciccarelli et al. 2013, Srinivasan 2015). The factors influencing motor variability have been linked to the characteristics of the operator and/or those of the task (see Gaudez et al. 2016 for review). However, although motor variability is made possible due to the large number of degrees of freedom resulting from the multiple joints involved in performing the task, it is also used more or less deliberately, and more or less consciously, by the person performing the task. Thus, one hypothesis proposed to explain the use of different strategies in the context of repetitive movement, is that, by differential muscle recruitment, it could allow mini rest phases for different muscle groups, which would reduce 
the risk of damaging soft tissues (Mathiassen 2006, Black et al. 2011, Boocock et al., 2015). Integrating these mini rest phases appears to suggest that they are taken into account by the operator when planning the movement. Indeed, planning is a central process which has been shown to be linked to variability (Churchland et al. 2006); it requires decision-making when faced with a choice of strategies. This decision-making involves analysis of the situation based on past experience. According to a recent study (Van den Berg et al., 2016), being confident of one's actions assists with decision-making, and it is reasonable to suppose that experience allows operators to acquire and reinforce this confidence.

Picking an object up off the ground is a movement which is performed nearly every day by everyone regardless of age or occupation. For this reason, the experience level for the part of the task requiring subjects to collect parts from floor-level can be considered to be similar for all operators, across all three age-groups. However, the decision to perform this movement using a particular strategy, selected from among several possible strategies is a costly neurological process which often leads subjects to reach a compromise between speed and precision (Drugowitsch et al., 2014, 2015). In this work, not only was the pace of work defined, but the instruction was that it had to be respected. Although subjects in the junior age-group were apparently able to readily adapt to changes of pace, older subjects, due to age-related changes in their functional capacities, had more difficulty (Gilles et al., 2017). Reducing the number of strategies used could be considered as a timesaver as it reduces the number of options to consider. Older subjects could already be using this means of saving time when performing tasks at the comfortable pace as they were seen to limit the number of strategies employed compared to younger subjects. This might explain why the slight reduction in the number of strategies at the fast pace appears more pronounced in the senior age group.

This analysis has some limitations, which should be considered. Indeed, several types of agglomerative hierarchical clustering methods exist, not all of which identify the same number of groups. The differences mainly affected the SRiKD class, where the characteristics of the three postures were very similar, and the overall number of groups may thus vary. Based on this observation, the variables selected for use in the analysis has an impact on the results. As mentioned above, if some of the variables chosen provide redundant information, the weight of this information will be overestimated, which will influence the result of the classification. Finally, the number of levels of dichotomies in the classification is determined by the researcher. All of these points mean that this type of analysis must be associated with an initial hypothesis. In this work, our initial hypothesis was suggested by visual observation of how subjects changed their strategy when collecting spare parts. These observations were supported by the qualitative comparison based on the video recordings and by quantitative information provided by the 3-D modelling analysis.

Nevertheless, a global analysis method has advantages when searching for movement variability. For example, through our analysis of the 3D models, we were able to take into account the disparity in the measurement of flexion or abduction angle for a lower limb joint. This disparity can be the result of variation in the postural configuration for several segments upstream and downstream of the joint in question. Because of its revelatory potential, this method should be more widely used to complete by-variable kinematic analyses. 


\section{Conclusion}

Using agglomerative hierarchical clustering, we identified seven bending strategies used when collecting elements stored at floor-level as part of an assembly task. These strategies were identified by simultaneous analysis of 17 kinematic variables. Our results indicated that most subjects used more than one bending strategy when performing the task, but that no specific strategy-type was associated with a particular age group or pace. However, we did observe that the number of strategies used by a subject decreased with increasing age. It therefore appears that the variability of the strategies used when performing repetitive movements is mainly influenced by age, while the effect of pace is less discernible. As assembly-line operators must repeatedly reproduce the same movement, decreased movement variability employed by senior workers may be a factor contributing to their higher risk of developing musculoskeletal disorders.

\section{References}

Anderson C.K., and Chaffin D.B. (1986). A biomechanical evaluation of five lifting techniques. Applied Ergonomics, 17, 2-8

Black N.L., Rickards J. and Sims R. (2011). Enhancing digital human modelling: Recognising variation in repetitive motion patterns. First International Symposium on Digital Human Modeling, Event of the Technical Committee on Human Simulation and Virtual Environment of the International Ergonomics Association, June 14-16, 2011, Lyon, France, 5 p.

Boocock M.G., Mawston G.A., Taylor S. (2015). Age-related differences do affect postural kinematics and joint kinetics during repetitive lifting. Clinical Biomechanics, 30, 136-143.

Bril B. (2015). Learning to use tools: A functional approach to action. Filliettaz L., Billett S. (eds.), Francophone perspectives of learning through work: conceptions, traditions and practices, Springer, 95-118

Bril B. et Goasdoué R. (2009). Du mouvement sans sens ou du sens sans mouvement : rôle des finalités et des contextes dans l'étude de comportements moteurs. Intellectica, 1, 51, 273-293

Burgess R.J., Hillier S., Keogh D., Kollmitzer J. and Oddsson L. (2009) Multi-segment trunk kinematics during a loaded lifting task for elderly and young subjects. Ergonomics, 52, 2, 222-231

Burgess-Limerick R. and Abernethy B. (1997). Toward a quantitative definition of manual lifting postures. Human Factors, 39, 1, 141-148

Burgess-Limerick R., Shemmell J., Barry B.K., Carson RG and Abernethy B. (2001). Spontaneous transitions in the coordination of a whole body task. Human Movement Science, 20, 4-5, 549-562

Ciccarelli M., Straker L., Mathiassen S.E. and Pollock C. (2013). Variation in muscle activity among office workers when using different information technologies at work and away-from-work. Human factors and ergonomics, 55, 5, 911-923

Churchland M.M., Afshar A. and Shenoy K.V. (2006). A central source of movement variability, Neuron, 52, 1085-1096 DOI 10.1016/j.neuron.2006.10.034 
de Looze, M.P., Dolan, P., Kingma, I., \& Baten, C.T.M. (1998). Does an asymmetric straddlelegged lifting movement reduce the low back load? Human Movement Science, 17, 243-259

Desrosiers J., Hebert R., Bravo G., Dutil E., (1995). The Purdue pegboard test: normative data for people aged 60 and over. Disability Rehabilitation 17, 5, 217-224

Duchateau J., Klass M. and Baudry S. (2006). Évolution et adaptations à l'entraînement du système neuromusculaire au cours du vieillissement. Science \& Sports 21, 4, 199-203

Drugowitsch J., DeAngelis G.C., Angelaki D.E., Pouget A. (2015). Tuning the speed-accuracy tradeoff to maximize reward rate in multisensory decision-making, eLIFE, 32p, DOI: http://dx.doi.org/10.7554/eLife.06678

Drugowitsch J., DeAngelis G.C., Klier E.M., Angelaki D.E., Pouget A. (2014). Optimal multisensory decision-making in a reaction-time task, eLIFE, 19p, DOI: http://dx.doi.org/10.7554/eLife.03005

Gaudez C., Gilles M.A. and Savin J. (2016). Intrinsic movement variability at work. How long is the path from motor control to design engineering? Applied Ergonomics, 53, 71-78

Gibo T.L., Bastian A.J. and Okamura A.M. (2013). Effect of age on stiffness modulation during postural maintenance of the arm. International Conference on Rehabilitation Robotics (ICORR), IEEE, 24-26 June 2013, 5p, DOI: 10.1109/ICORR.2013.6650395

Gilles M.A., Guelin J.C., Desbrosses K. and Wild P. (2017). Motor adaptation capacity as a function of age in carrying out a repetitive assembly task at imposed work paces. Applied Ergonomics, 64, 4755

Hagen K.B. and Harms-Ringdahl K. (1994). Ratings of perceived thigh and back exertion in forest workers during repetitive lifting using squat and stoop techniques. Spine, 19, 2511-2517

Hanavan E.P. (1964). A mathematical model of the human body. A.F. Base Ohio; Aero Medical Research Laboratories Technical Report. 73p

Hoozemans M.J.M., Kingma I., de Vries W.H., van Dieën J.H. (2008). Effect of lifting height and load mass on low back loading. Ergonomics, 51, 7, 1053-1063

Kumar S. (1984). The physiological cost of three different methods of lifting in sagittal and lateral planes. Ergonomics, 27, 4, 425-433

Lin C.J., Bernard T.M. and Ayboud M.M. (1999). A biomechanical evaluation of lifting speed using work- and moment-related measures, Ergonomics, 42, 8, 1051-1059

Lindbeck L. and Kjellberg K. (2001). Gender differences in lifting technique. Ergonomics, 44, 2 , 202-214

Macaluso A. and De Vito G. (2004). Muscle strength, power and adaptations to resistance training in older people. European Journal of Applied Physiology 91, 4, 450-472 
Madeleine P. (2010). On functional motor adaptations: from the quantification of motor strategies to the prevention of musculoskeletal disorders in the neck-shoulder region. Acta Physiologica, 199, 146

Madeleine P. and Madsen T. M. T. (2009). Changes in the amount and structure of motor variability during a deboning process are associated with work experience and neck-shoulder discomfort. Applied Ergonomics, 40, 887-894

Mathiassen S.E. (2006). Diversity and variation in biomechanical exposure: what is it, and why would we like to know? Applied Ergonomics. 37, 419-427

Mathiassen S.E. and Paquet V. (2010). The ability of limited exposure sampling to detect effects of interventions that reduce the occurrence of pronounced trunk inclination. Applied Ergonomics, 41, 2, 295-304

Plamondon A., Delisle A., Bellefeuille S., Denis D., Gagnon D., Larivière C. (2014a). Lifting strategies of expert and novice workers during a repetitive palletizing task. Applied Ergonomics, 45, 471-481

Plamondon A., Denis D., Delisle A., Larivière C., Salazar E. (2010). Biomechanical differences between expert and novice workers in a manual material handling task. Ergonomics, 53, 10, 12391253

Plamondon A., Larivière C., Denis D., St-Vincent M., Delisle A. (2014b). Sex differences in lifting strategies during a repetitive palletizing task. Applied Ergonomics, 45, 1558-1569

Sheppard P.S. (2012). Sex-based differences in lifting technique under increasing load conditions: A principal component analysis Thesis, $125 \mathrm{p}$

Sheppard P.S., Stevenson J.M., Graham R.B. (2016). Sex-based differences in lifting technique under increasing load conditions: A principal component analysis. Applied Ergonomics, 54, 186-195

Srinivasan D., Mathiassen S.E. (2012). Motor variability in occupational health and performance. Clinical Biomechanics, 27, 979-993

Srinivasan D., Rudolfsson T. and Mathiassen S.E. (2015). Between- and within-subject variance of motor variability metrics in females performing repetitive upper-extremity precision work. Journal of Electromyography and Kinesiology, 25, 1, 121-129

Rosenbaum D.A., Meulenbroek R.J., Vaughan J. and Chris J. (2001). Posture-based motion planning: Applications to grasping. Psychological Review, 108, 4, 709-734

Straker L. (2003). Evidence to support using squat, semi-squat and stoop techniques to lift low lying objects. International Ergonomics, 31, 149-160

Shin G. , Nance M.L., Mirka G.A. (2006). Differences in trunk kinematics and ground reaction forces between older and younger adults during lifting. International Journal of Industrial Ergonomics, 36, 767-772 
Song J. and Qu X. (2014). Effects of age and its interaction with task parameters on lifting biomechanics. Ergonomics, 57, 5, 653-668

Trafimow J.H., Schipplein O.D., Novak G.J. and Anderson G.B.J. (1993). The effects of quadriceps fatigue on the technique of lifting. Spine, 18, 3, 364-367

van den Berg R., Zylberberg A., Kiani R., Shadlen M.N. and Wolpert D.M. (2016). Confidence is the bridge between multi-stage decisions. Current Biology, 26, 23, 3157-3168

Van Dieën J.H., Creemers M., Draisma I. (1994). Repetitive lifting and spinal shrinkage, effects of age and lifting technique. Clinical Biomechanics, 9, 367-374

van Dieën J.H., Hoozemans M.J.M. and Toussaint H. M. (1999). Stoop and squat: A review of biomechanical studies on lifting technique. Clinical Biomechanics, 14, 685-696

Wahlstrom J., Mathiassen S.E., Liv P., Hedlund P., Ahlgren C. and Forsman M. (2010). Upper arm postures and movements in female hairdressers across four full working days. Annals of Occupational Hygiene 54, 5, 584 - 594

Wu G., Siegler S., Allard P., Kirtley C., Leardini A., Rosenbaum D., Whittle M., D’lima D.D., Cristofolini L., Witte H., Schmid O. and Stokes I. (2002). ISB recommendation on definitions of joint coordinate system of various joints for the reporting of human joint motion — part I: ankle, hip, and spine. J Biomech. 35, 543-548

Wu G. and Cavanagh P.R. (1995). ISB recommendations for standardization in the reporting of kinematic data. J Biomech. 28, 1257-1261 


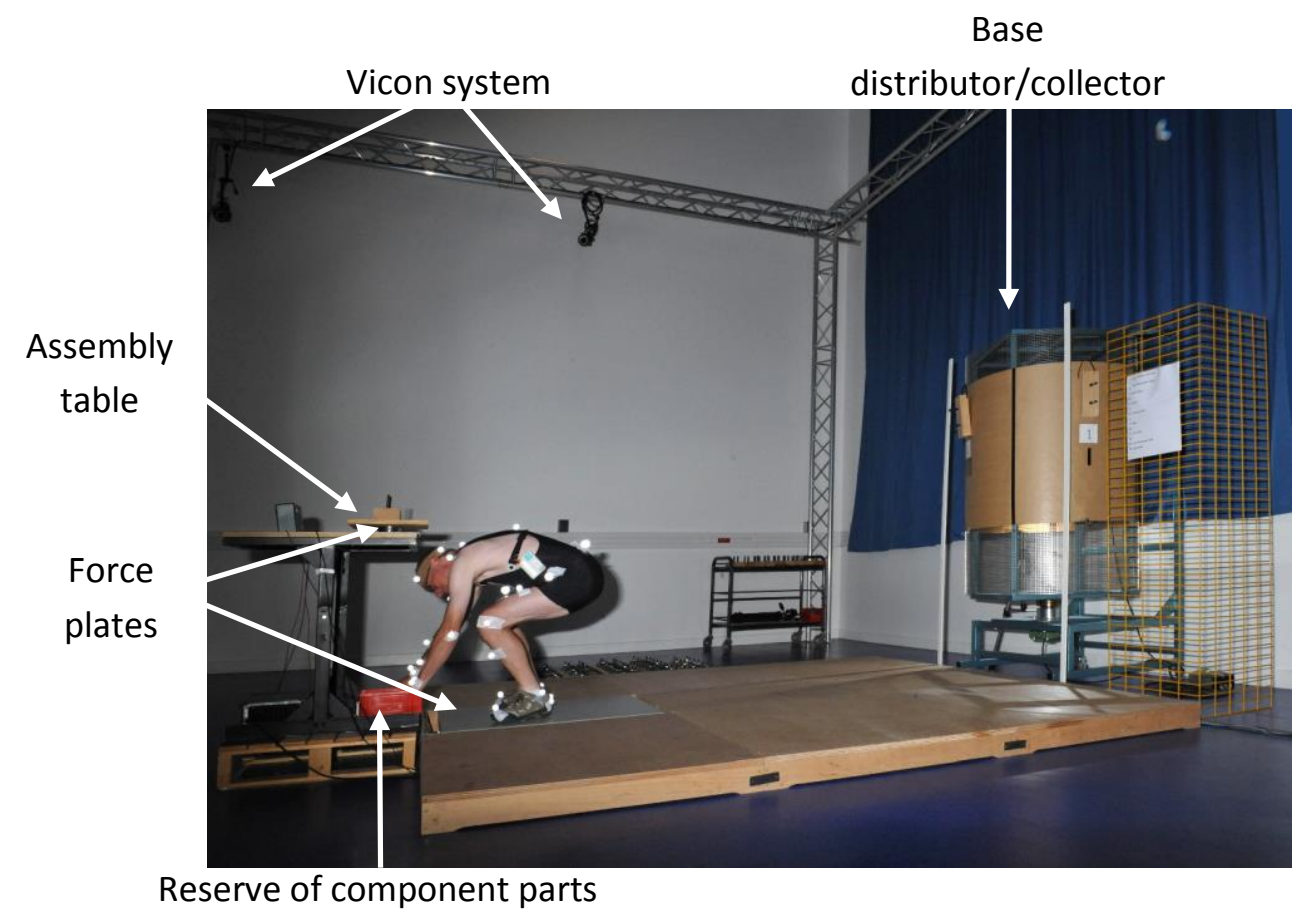

Figure 1: Experimental set-up used during the assembly task. Participants started near the table. They had to go to the distributor to collect a base part. Then, they had to go back to the work station where they had to fetch component parts stored under the table. All parts were assembled together on the assembly table. Upon completion of the assembly, participants had to place it on the distributor/collector and immediately start a new assembly cycle. This paper only deals with the part of the assembly where subjects collected the component parts stored under the table. 


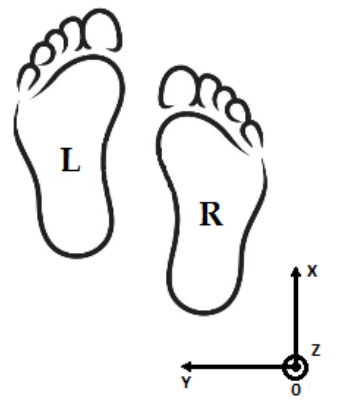

a - Coordinate system; left $(L)$ and right $(R)$ foot

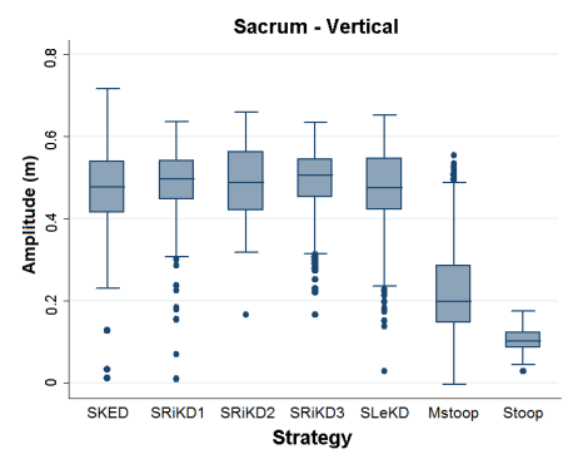

$b$ - Amplitude of vertical displacement of the joint centre for the sacrum
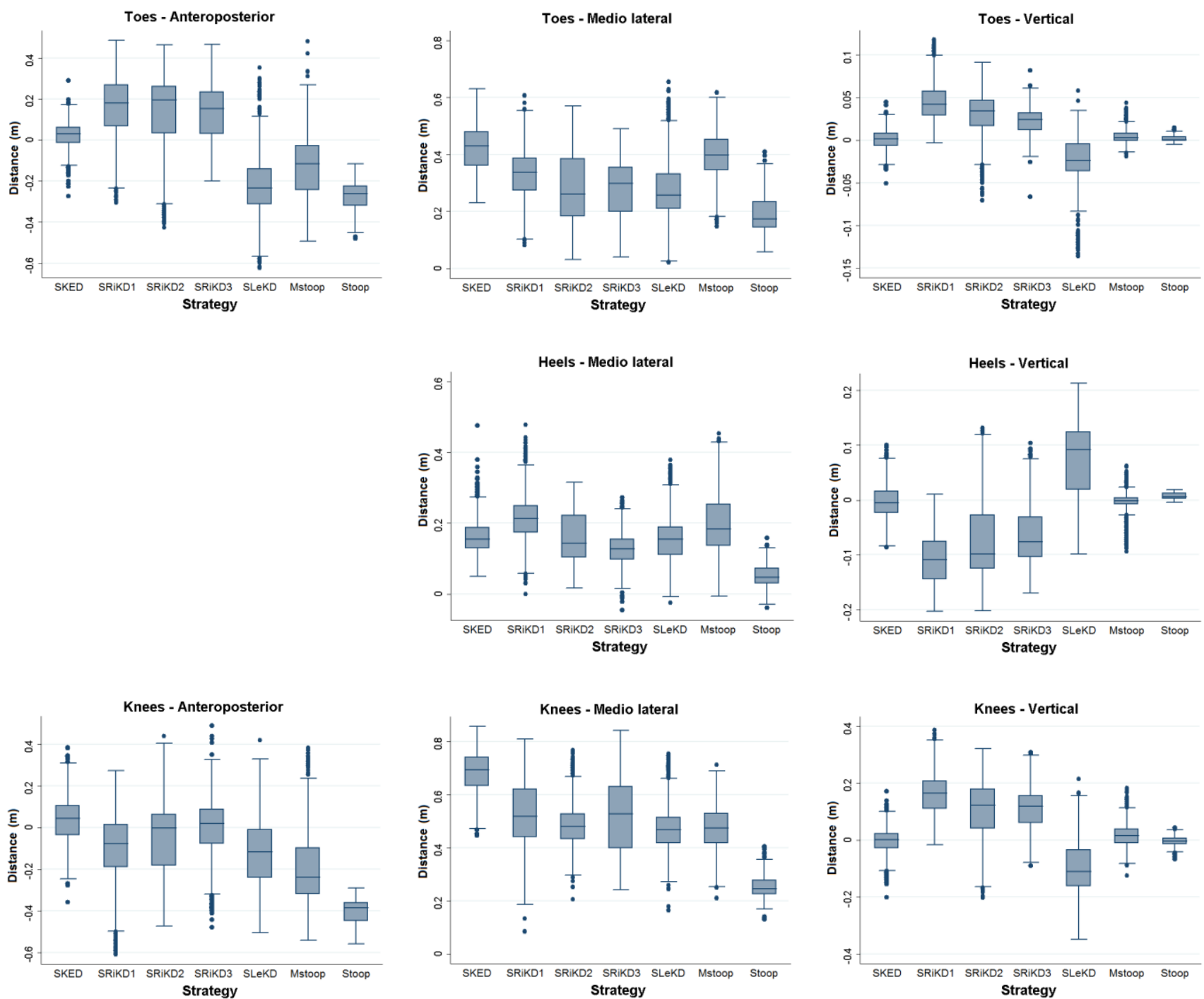

c - Distance between joint centres on the left and right lower limbs. A positive value indicates that the left side was positioned to the fore of the anteroposterior axis, or above the vertical axis. 

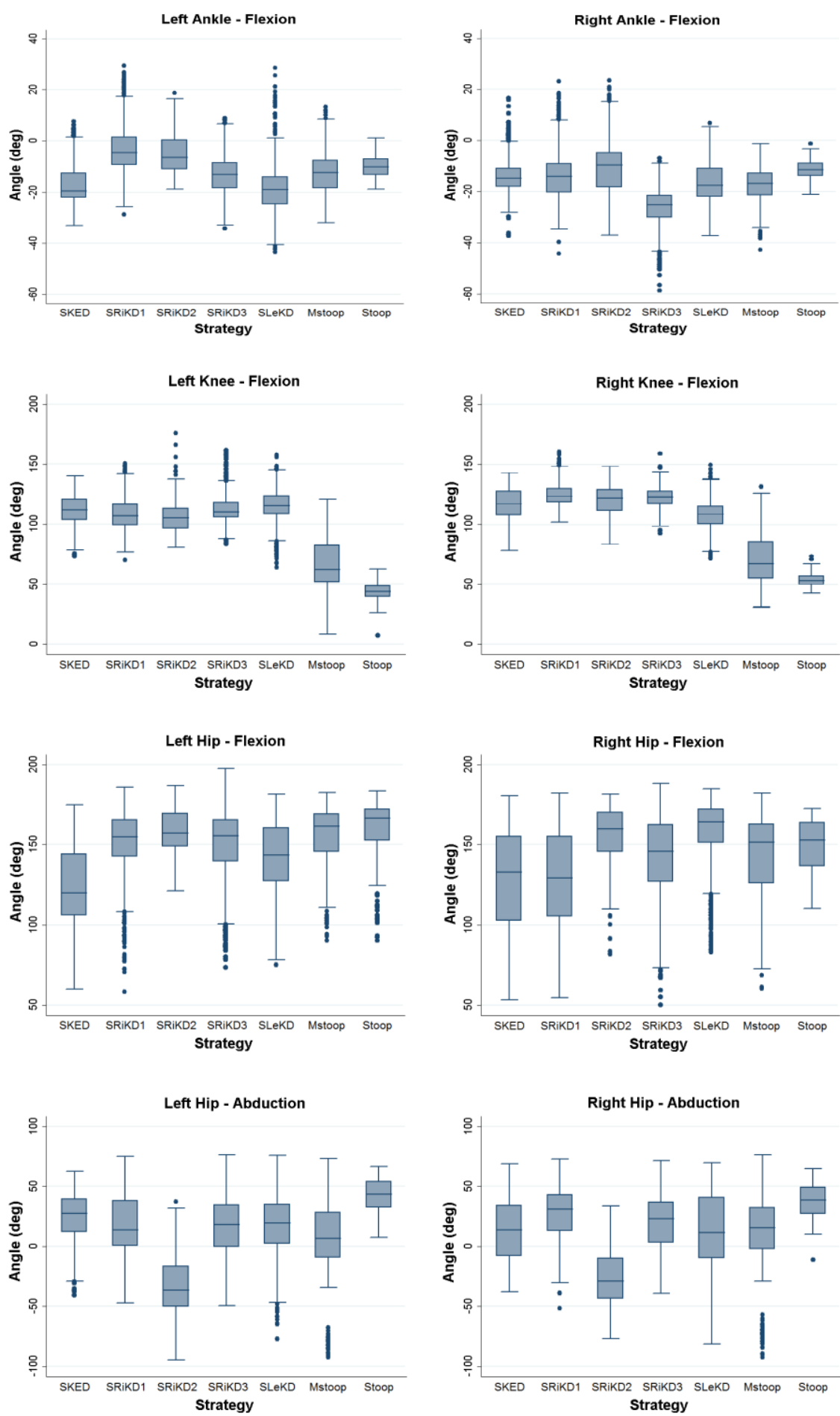

$d$ - Inter-segment angles measured for the lower limbs

Figure 2: Distribution of the 17 variables based on the seven strategies identified by the agglomerative hierarchical clustering. a- Reference measurement used in the experiments; bAmplitude of downward movement of the sacrum; c- Anteroposterior, medio-lateral and vertical distances between the toes, heels and knees relative to appropriate reference planes; d- Angles of flexion at the ankles, knees and hips, and abduction angles at the hips. Distances and inter-segment angles were measured when the sacrum was located at its lowest point relative to the ground. Strategies: SKED: squat knees equally descended; SRiKD1: squat right knee down 1; SRiKD2: squat right knee down 2; SRiKD3: squat right knee down 3; SLeKD: squat left knee down; MStoop: midstoop; Stoop. 


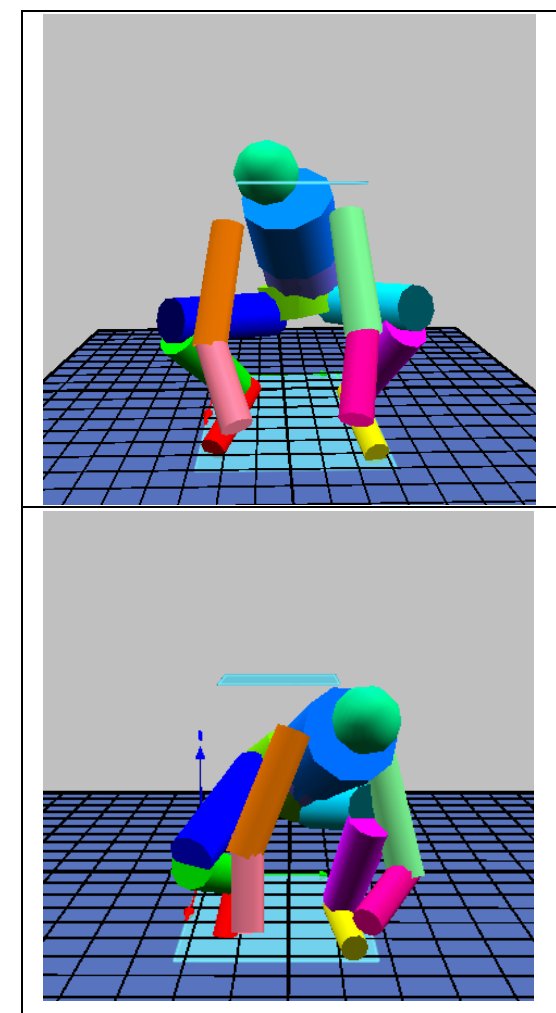

Squat Knees Equally Descended (SKED):

Sacrum significantly lowered relative to initial position. The toes are relatively well-aligned in the anteroposterior direction and are quite widely-spaced. The heels are positioned vertically at the same level. The knees present only slight anteroposterior displacement but have the most extensive lateral spacing observed, vertically they are placed at the same level. The angles of flexion for the ankles, knees and hips are relatively symmetrical between the right and the left. Abduction of the hips is also relatively symmetrical.

Squat Right Knee Down 1 (SRiKD1):

Sacrum significantly lowered relative to initial position. The right foot is placed behind the left foot. The toes are more widely-spaced than the heels. Based on the vertical positions of the toes and heels, the right foot is flexed, with the heel raised, whereas the left foot is placed flat on the floor. The right knee is placed forward the left and has a lower position. Ankle extension and knee flexion are $\mathrm{n}$ the right side. Flexion of the hips is greater on the left, but on the right there is significant variability. Hip abduction indicates opening of the right thigh towards the exterior whereas the left hip remains closer to the body's mid-line.

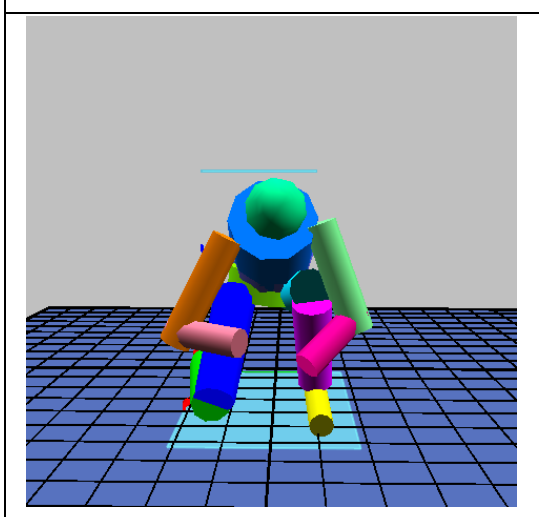

\section{Squat Right Knee Down 2 (SRiKD2):}

Sacrum significantly lowered relative to initial position. The right foot is placed behind the left foot. The toes are more widely-spaced than the heels. Based on the vertical positions of the toes and heels, the right foot is flexed, with the heel raised, whereas the left foot is placed flat on the floor. The knees are aligned in the anteroposterior direction; the level of dispersion tends to place the right knee in front. The left knee is higher than the right. Ankle extension and knee flexion are on the right side. The flexions and abduction of the left and right hips are symmetrical. This is the only strategy that presents significant abduction of the hips.

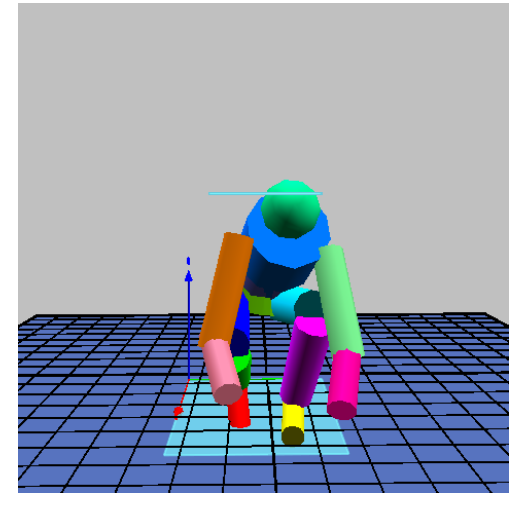

Squat Right Knee Down 3: (SRiKD3)

Sacrum significantly lowered relative to initial position. The right foot is placed behind the left foot. The toes are more widely-spaced than the heels. Based on the vertical positions of the toes and heels, the right foot is flexed, with the heel raised, whereas the left foot is placed flat on the floor. The right heel is not as high as in the two previous strategies. The knees are aligned in the anteroposterior plane and present significant dispersion in terms of medio-lateral spacing. The left knee is higher than the right. Right ankle presents the largest extension observed. Flexion of the knees is relatively symmetrical, like that of the hips. Opening of the hip is more marked on the right. 

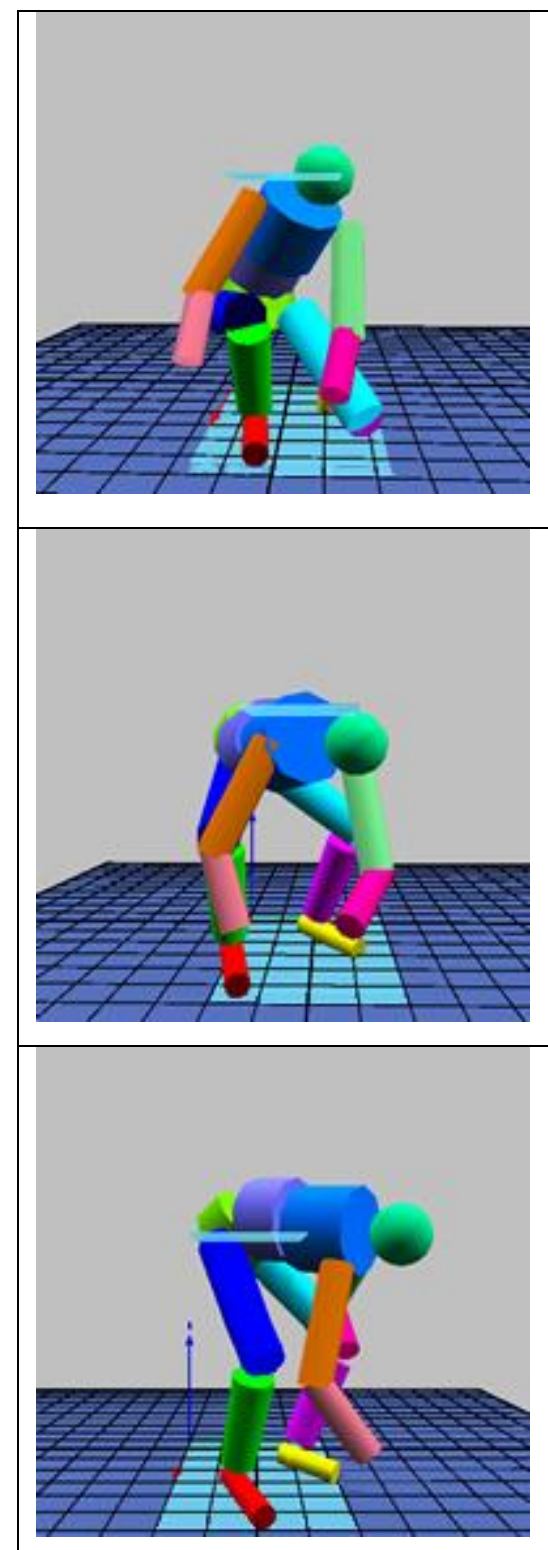

\section{Stoop}

The amplitude of downwards movement of the sacrum is the smallest observed, with a very small dispersion. The left foot is placed behind the right foot and lateral spacing of the toes and heels is the smallest observed. There are no differences in the vertical levels of the toes or heels, with a very small dispersion in both cases. The two feet are placed flat on the floor. The right knee is placed posterior to the left. The lateral spacings between the toes, the heels and the knees are the smallest observed. No difference in vertical placement of the knees is observed. Flexion of the ankles and knees are symmetrical and slight. Flexion at the knees is the smallest observed, with very little dispersion. Flexion of the hips is greater on the left. The abduction is the largest observed and symmetrical between left and right.

Figure 3: Definitions of the seven strategies identified by agglomerative hierarchical clustering based on analysis of the box plots. 


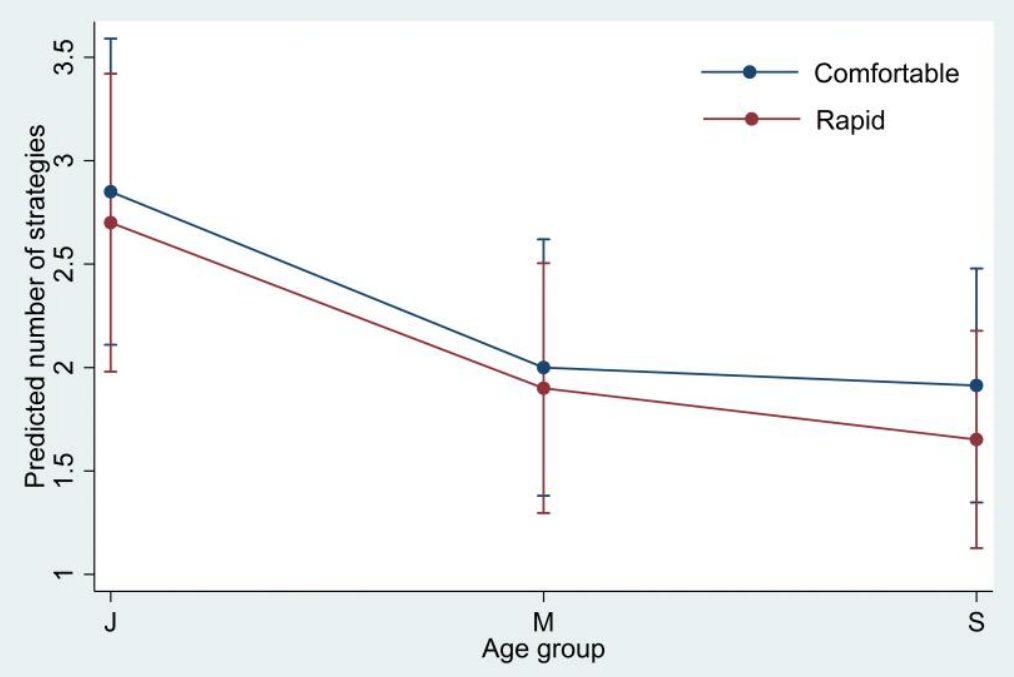

Figure 4: The number of strategies used decreases with age but is unaffected by pace. Modelpredicted number of strategies used with $95 \%$ CIs by age and pace. 


\begin{tabular}{|l|l|l|l|}
\hline Characteristic & \multicolumn{1}{|c|}{ Junior } & \multicolumn{1}{c|}{ Median } & \multicolumn{1}{c|}{ Senior } \\
\hline Number of subjets & 20 & 20 & 23 \\
\hline Age (years) & 32.6 & 47.1 & 61.8 \\
& $(30-35)$ & $(45-50)$ & $(60-65)$ \\
\hline Body mass $(\mathrm{kg})$ & 74.9 & 78.8 & 81.2 \\
& $(53-103)$ & $(60-110)$ & $(62-106)$ \\
\hline Height (m) & 1.77 & 1.75 & 1.74 \\
& $(1.55-1.87)$ & $(1.63-1.91)$ & $1.65-1.88)$ \\
\hline Body Mass Index & 23.9 & 25.6 & 26.9 \\
& $(19.7-34.5)$ & $(20.6-34.6)$ & $(21.0-35.5)$ \\
\hline
\end{tabular}

Table 1: Characteristics of the subjects in the different age-groups. Values are expressed as mean (range). Differences in body mass and height were not significant. The body mass index for the Junior group was significantly different from that for the Senior group (ANOVA $p=0.038$. 


\section{Comfortable pace}

\begin{tabular}{|c|c|c|c|c|c|c|c|c|}
\hline \multirow{2}{*}{$\begin{array}{l}\text { Age } \\
\text { group }\end{array}$} & \multicolumn{7}{|c|}{ Strategy } & \multirow[t]{2}{*}{ Total } \\
\hline & SKED & SRiKD1 & SRiKD2 & SRiKD3 & SLeKD & MStoop & Stoop & \\
\hline $\begin{array}{c}\mathrm{N} \\
\%\end{array}$ & $\begin{array}{l}3 \\
15.0\end{array}$ & $\begin{array}{l}5 \\
25.0\end{array}$ & $\begin{array}{l}1 \\
5.0\end{array}$ & $\begin{array}{l}7 \\
35.0\end{array}$ & $\begin{array}{l}2 \\
10.0\end{array}$ & $\begin{array}{l}2 \\
10.0\end{array}$ & - & $\begin{array}{l}20 \\
100\end{array}$ \\
\hline $\begin{array}{ll}\mathrm{M} & \mathrm{N} \\
& \%\end{array}$ & $\begin{array}{l}1 \\
5.0\end{array}$ & $\begin{array}{l}5 \\
25.0\end{array}$ & $\begin{array}{l}4 \\
20.0\end{array}$ & $\begin{array}{l}4 \\
20.0\end{array}$ & $\begin{array}{l}5 \\
25.0\end{array}$ & - & $\begin{array}{l}1 \\
5.0\end{array}$ & $\begin{array}{l}20 \\
100\end{array}$ \\
\hline $\begin{array}{|cc|}\mathrm{S} & \mathrm{N} \\
& \% \\
\end{array}$ & $\begin{array}{l}2 \\
8.7 \\
\end{array}$ & $\begin{array}{l}3 \\
13.0 \\
\end{array}$ & $\begin{array}{l}3 \\
13.0\end{array}$ & $\begin{array}{l}2 \\
8.7\end{array}$ & $\begin{array}{l}6 \\
26.1 \\
\end{array}$ & $\begin{array}{l}6 \\
26.1\end{array}$ & $\begin{array}{l}1 \\
4.4\end{array}$ & $\begin{array}{l}23 \\
100\end{array}$ \\
\hline $\begin{array}{r}\text { Total } \mathrm{N} \\
\%\end{array}$ & $\begin{array}{l}6 \\
9.6\end{array}$ & $\begin{array}{l}13 \\
20.6\end{array}$ & $\begin{array}{l}8 \\
12.7\end{array}$ & $\begin{array}{l}13 \\
20.6\end{array}$ & $\begin{array}{l}13 \\
20.6\end{array}$ & $\begin{array}{l}8 \\
12.7\end{array}$ & $\begin{array}{l}2 \\
3.2\end{array}$ & $\begin{array}{l}63 \\
100\end{array}$ \\
\hline
\end{tabular}

Fisher's exact test $\mathrm{p}=0.157$

\section{Rapid pace}

\begin{tabular}{|c|c|c|c|c|c|c|c|c|}
\hline \multirow{2}{*}{$\begin{array}{l}\text { Age } \\
\text { group }\end{array}$} & \multicolumn{7}{|c|}{ Strategy } & \multirow[t]{2}{*}{ Total } \\
\hline & SKED & SRiKD1 & SRiKD2 & SRiKD3 & SLeKD & MStoop & Stoop & \\
\hline $\begin{array}{ll}\mathrm{J} & \mathrm{N} \\
& \%\end{array}$ & $\begin{array}{l}1 \\
5.0\end{array}$ & $\begin{array}{l}4 \\
20.0\end{array}$ & - & $\begin{array}{l}11 \\
55.0\end{array}$ & $\begin{array}{l}2 \\
10.0\end{array}$ & $\begin{array}{l}2 \\
10.0\end{array}$ & - & $\begin{array}{l}20 \\
100\end{array}$ \\
\hline $\begin{array}{ll}\mathrm{M} & \mathrm{N} \\
& \%\end{array}$ & $\begin{array}{l}1 \\
5.0\end{array}$ & $\begin{array}{l}7 \\
35.0\end{array}$ & $\begin{array}{l}1 \\
5.0\end{array}$ & $\begin{array}{l}4 \\
20.0\end{array}$ & $\begin{array}{l}6 \\
30.0\end{array}$ & $\begin{array}{l}1 \\
5.0\end{array}$ & - & $\begin{array}{l}20 \\
100\end{array}$ \\
\hline $\begin{array}{ll}\mathrm{S} & \mathrm{N} \\
& \%\end{array}$ & $\begin{array}{l}4 \\
17.4\end{array}$ & $\begin{array}{l}4 \\
17.4\end{array}$ & - & $\begin{array}{l}3 \\
13.0\end{array}$ & $\begin{array}{l}6 \\
26.1\end{array}$ & $\begin{array}{l}5 \\
21.7\end{array}$ & $\begin{array}{l}1 \\
4.4\end{array}$ & $\begin{array}{l}23 \\
100\end{array}$ \\
\hline $\begin{array}{r}\text { Total } \mathrm{N}_{\%}\end{array}$ & $\begin{array}{l}6 \\
9.5\end{array}$ & $\begin{array}{l}15 \\
23.8\end{array}$ & $\begin{array}{l}1 \\
1.6\end{array}$ & $\begin{array}{l}18 \\
28.6\end{array}$ & $\begin{array}{l}14 \\
22.2\end{array}$ & $\begin{array}{l}8 \\
12.7\end{array}$ & $\begin{array}{l}1 \\
1.6\end{array}$ & $\begin{array}{l}63 \\
100\end{array}$ \\
\hline
\end{tabular}

Fisher's exact test $\mathrm{p}=0.063$

Table 2: Dominant strategies used by each age-group at the two work paces: e.g. at the rapid pace, the SKED strategy is the most used by only one subject in the young age-group. It thus represents $5 \%$ of the dominant strategies for this age-group. $\mathrm{N}=$ number of subjects; $\mathrm{J}=$ junior; $\mathrm{M}=$ median; $\mathrm{S}=$ senior age-group. 


\section{Comfortable pace}

\begin{tabular}{|c|c|c|c|c|c|c|}
\hline \multirow{2}{*}{$\begin{array}{l}\text { Group } \\
\text { age }\end{array}$} & \multicolumn{5}{|c|}{ Number of strategies used } & \multirow{3}{*}{$\begin{array}{l}\text { Total } \\
20 \\
100\end{array}$} \\
\hline & 1 & 2 & 3 & 4 & 5 & \\
\hline $\begin{array}{l}\mathrm{N} \\
\% \\
\end{array}$ & $\begin{array}{l}1 \\
5.0\end{array}$ & $\begin{array}{l}9 \\
45.0 \\
\end{array}$ & $\begin{array}{l}5 \\
25.0 \\
\end{array}$ & $\begin{array}{l}2 \\
10.0 \\
\end{array}$ & $\begin{array}{l}3 \\
15.0 \\
\end{array}$ & \\
\hline $\begin{array}{ll}\mathrm{M} & \mathrm{N} \\
& \%\end{array}$ & $\begin{array}{l}6 \\
30.0\end{array}$ & $\begin{array}{l}8 \\
40.0\end{array}$ & $\begin{array}{l}6 \\
30.0\end{array}$ & - & - & $\begin{array}{l}20 \\
100\end{array}$ \\
\hline $\begin{array}{ll}\mathrm{S} & \mathrm{N} \\
\%\end{array}$ & $\begin{array}{l}10 \\
43.5\end{array}$ & $\begin{array}{l}6 \\
26.1\end{array}$ & $\begin{array}{l}6 \\
26.1\end{array}$ & $\begin{array}{l}1 \\
4.3\end{array}$ & - & $\begin{array}{l}23 \\
100\end{array}$ \\
\hline $\begin{array}{c}\text { Total } \mathrm{N} \\
\%\end{array}$ & $\begin{array}{l}17 \\
27.0\end{array}$ & $\begin{array}{l}23 \\
36.4\end{array}$ & $\begin{array}{l}17 \\
27.0\end{array}$ & $\begin{array}{l}3 \\
4.8\end{array}$ & $\begin{array}{l}3 \\
4.8 \\
\end{array}$ & $\begin{array}{l}63 \\
100 \\
\end{array}$ \\
\hline
\end{tabular}

Fisher's exact test $\mathrm{p}=0.039$

\section{Rapid pace}

\begin{tabular}{|c|c|c|c|c|c|c|}
\hline \multirow{2}{*}{$\begin{array}{l}\text { Group } \\
\text { age }\end{array}$} & \multicolumn{5}{|c|}{ Number of strategies used } & \multirow[t]{2}{*}{ Total } \\
\hline & 1 & 2 & 3 & 4 & 5 & \\
\hline $\begin{array}{ll}\mathrm{J} & \mathrm{N} \\
\%\end{array}$ & $\begin{array}{l}5 \\
25.0\end{array}$ & $\begin{array}{l}5 \\
25.0\end{array}$ & $\begin{array}{l}5 \\
25.0\end{array}$ & $\begin{array}{l}1 \\
5.0\end{array}$ & $\begin{array}{l}4 \\
20\end{array}$ & $\begin{array}{l}20 \\
100\end{array}$ \\
\hline $\begin{array}{ll}\mathrm{M} & \mathrm{N} \\
& \% \\
\end{array}$ & $\begin{array}{l}4 \\
20 \\
\end{array}$ & $\begin{array}{l}14 \\
70 \\
\end{array}$ & $\begin{array}{l}2 \\
10 \\
\end{array}$ & - & - & $\begin{array}{l}20 \\
100\end{array}$ \\
\hline $\begin{array}{ll}\mathrm{S} & \mathrm{N} \\
& \%\end{array}$ & $\begin{array}{l}12 \\
52.2\end{array}$ & $\begin{array}{l}8 \\
34.8\end{array}$ & $\begin{array}{l}2 \\
8.7\end{array}$ & $\begin{array}{l}1 \\
4.3\end{array}$ & - & $\begin{array}{l}23 \\
100\end{array}$ \\
\hline $\begin{array}{c}\text { Total } \mathrm{N} \\
\%\end{array}$ & $\begin{array}{l}21 \\
33.3\end{array}$ & $\begin{array}{l}27 \\
42.8\end{array}$ & $\begin{array}{l}9 \\
14.3\end{array}$ & $\begin{array}{l}2 \\
3.2\end{array}$ & $\begin{array}{l}4 \\
6.4\end{array}$ & $\begin{array}{l}63 \\
100\end{array}$ \\
\hline
\end{tabular}

Fisher's exact test $\mathrm{p}=0.007$

Table 3: Number of strategies used by each age-group at the two work paces: e.g. at the rapid pace, 5 members $(25 \%)$ of the junior age-group only used a single strategy. $\mathrm{N}=$ number of subjects; $\mathrm{J}=$ junior; $\mathrm{M}=$ median; $\mathrm{S}=$ senior age-group. 